\title{
Nacre Topography Produces Higher Crystallinity in Bone than Chemically Induced Osteogenesis
}

\author{
Enateri V. Alakpa, ${ }^{\dagger}$ Karl E. V. Burgess, ${ }^{\ddagger}$ Peter Chung, ${ }^{\dagger}$ Mathis O. Riehle, ${ }^{\S}$ Nikolaj Gadegaard, ${ }^{\|(}$
} Matthew John Dalby, ${ }^{*} \S$ and Maggie Cusack ${ }^{*}, \perp \infty$

${ }^{\dagger}$ School of Geographical and Earth Sciences, College of Science and Engineering, University of Glasgow, Gregory Building, Glasgow G12 8QQ United Kingdom

${ }^{\ddagger}$ Scottish Polyomics Facility, Wolfson Wohl Cancer Research Centre, College of Medical, Veterinary, and Life Sciences, University of Glasgow, Garscube Estate, Glasgow G61 1QH, United Kingdom

${ }^{\S}$ Centre for Cell Engineering, Institute of Molecular, Cell, and Systems Biology, College of Medical, Veterinary, and Life Sciences, University of Glasgow, Joseph Black Building, Glasgow G12 8QQ, United Kingdom

"Division of Biomedical Engineering, School of Engineering, University of Glasgow, Glasgow G12 8LT, United Kingdom

${ }^{\perp}$ Division of Biological and Environmental Sciences, Faculty of Natural Sciences, University of Stirling, Cottrell Building, Stirling FK9 4LA, United Kingdom

\section{Supporting Information}

ABSTRACT: It is counterintuitive that invertebrate shells can induce bone formation, yet nacre, or mother of pearl, from marine shells is both osteoinductive and osteointegrative. Nacre is composed of aragonite (calcium carbonate) and induces production of vertebrate bone (calcium phosphate). Exploited by the Mayans for dental implants, this remarkable phenomenon has been confirmed in vitro and in vivo, yet the characteristic of nacre that induces bone formation remains unknown. By isolating nacre topography from its inherent chemistry in the production of polycaprolactone (PCL) nacre replica, we show that, for mesenchymal stem cells, nacre topography is osteoinductive. Gene expression of specific bone marker proteins, osteopontin, osteocalcin, osteonectin, and osterix, is increased 10-, 2-, 1.7-, and 1.8-fold, respectively, when compared to planar PCL. Furthermore, we demonstrate that bone tissue that forms in response to the physical topographical features of nacre has a higher crystallinity than bone formed in response to chemical cues with a full width half-maximum for $\mathrm{PO}_{4}{ }^{3-}$ Raman shift of $7.6 \pm 0.7$ for mineral produced in response to nacre replica compared to a much broader $34.6 \pm 10.1$ in response to standard osteoinductive medium. These differences in mineral product are underpinned by differences in cellular metabolism. This observation can be exploited in the design of bone therapies; a matter that is most pressing in light of a rapidly aging human population.

KEYWORDS: biomaterials, bone, differentiation, nacre, osteogenesis

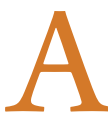

ragonite and calcite are the two calcium carbonate polymorphs that constitute the shell of molluscan bivalves conferring strength and resilience due to the nano- and microstructural assembly of the overall architecture. ${ }^{1}$ A small percentage of the invertebrate shell constitutes the organic matrix ${ }^{2,3}$ which is responsible for the intricate processes of nucleation, growth, and inhibition of calcium carbonate crystals resulting in the well-defined shell structure. ${ }^{4-8}$

The discovery of fully integrated shell dental implants in Mayan skulls ${ }^{9}$ initiated a number of studies showing that nacre, or mother of pearl, the aragonite calcium carbonate polymorph derived from the pearl oyster Pinctada maxima has good osteointegrative properties in vivo. ${ }^{10-13}$ Further exploration of this phenomenon in human jaw reconstructions and sheep femur implants ${ }^{10,11,14}$ confirms the osteointegrative properties of invertebrate shells. In addition, nacre initiates osteogenic

Received: February 14, 2017

Accepted: June 30, 2017

Published: June 30, 2017 

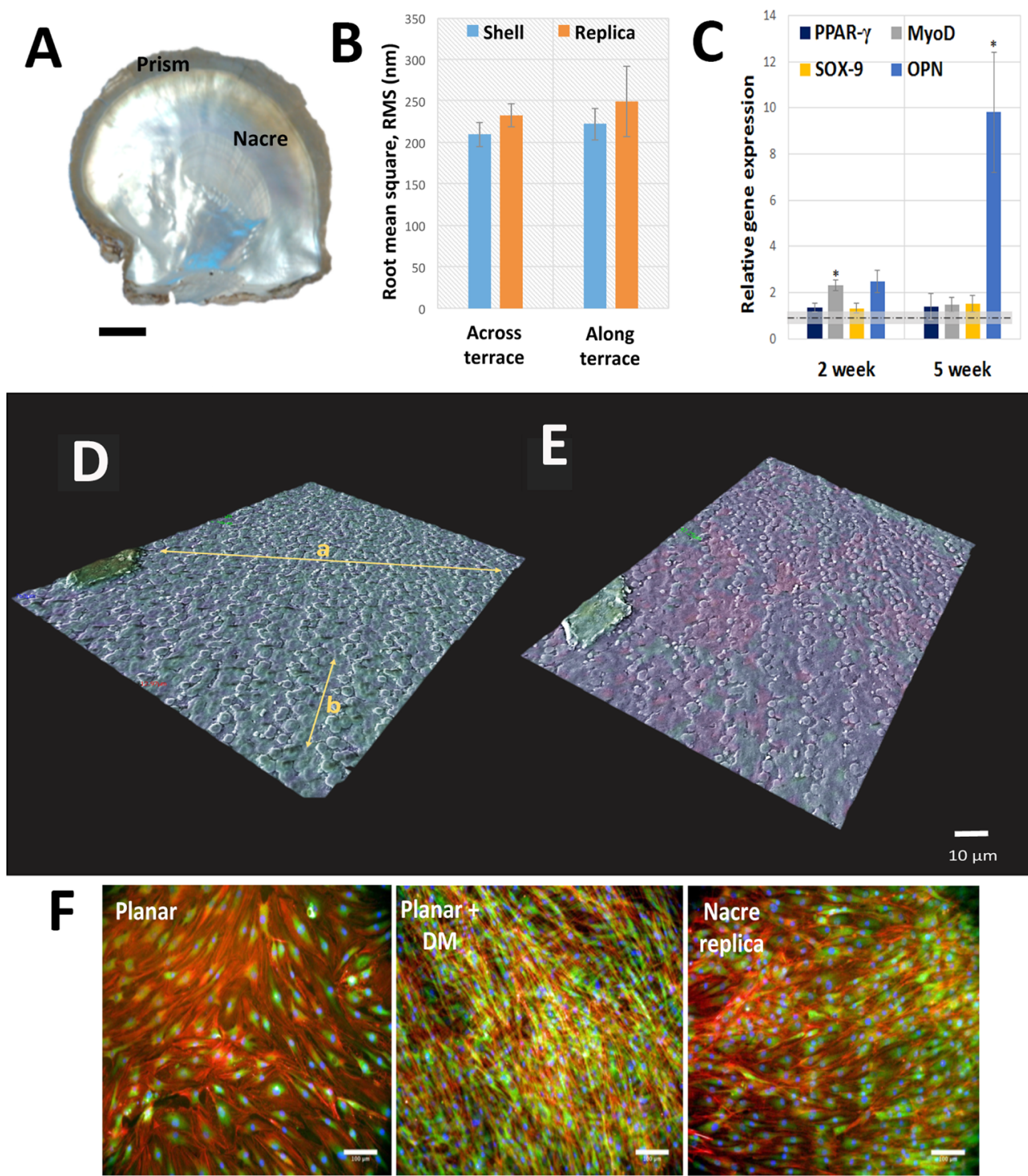

Figure 1. Osteogenic response of MSCs to high fidelity nacre replica. (A) Internal view of a single valve of a Pinctada maxima shell showing the prismatic (calcite) and the nacreous (aragonite) surface region. (B) Average surface roughness $\left(R_{\mathrm{q}}\right)$ measured using digital elevation models from SEM images of the shell nacre region (D) and its equivalent replicated PCL regions (E). Replicated patterns of nacre show high fidelity to the original shell nacre. Measurements to determine average surface roughness $(n=6)$ were taken at random across $(x)$ and along (y) terraces of nacre. (C) Gene transcription analysis of MSCs cultured on PCL replicas of nacre topography. Cells were cultured up to 2 and 5 weeks and then assessed for development along typical mesenchyme lineages (PPAR- $\gamma$, adipogenesis; MyoD, myogenesis; SOX-9, chondrogenesis; and OPN, osteogenesis). OPN expression levels increased over time on the nacre replica surfaces indicating osteogenic development. The dashed line represents the control (planar PCL) which is held nominally at 1 . Error bars denote standard errors from the mean, and * indicates statistical significance compared to the planar substrate calculated using Mann-Whitney $\mathrm{U}$ test $n=6$. (F) Immunofluorescence staining of MSCs cultured on planar PCL surfaces in the absence (Planar) or presence of osteospecific differentiating media (Planar + DM) as negative and positive controls, respectively. Cells cultured in differentiating media and on nacre replica topography showing increased expression of osteopontin (green) compared to undifferentiated cells on the planar substrate. Cells were also stained for cell nucleus (blue) and f-actin (red). Scale bars in (A) $3 \mathrm{~cm}$, (D and E) $10 \mu \mathrm{m}$, and (F) $100 \mu \mathrm{m}$.

differentiation in mesenchymal stem cells (MSCs) in vitro. ${ }^{15-17}$ This observation has led to a number of studies in which nacre and its chemistry have been incorporated into the design of existing biomaterials to induce bone formation. ${ }^{15,18-20}$

MSCs can be induced into undergoing osteogenesis in vitro by the use of preformulated soluble factors in the culture media, ${ }^{21-25}$ chemically defined surfaces, ${ }^{26,27}$ substrate matrix elasticity, ${ }^{28-34}$ and the surface topography of the substrate. ${ }^{35-39}$ These approaches induce osteogenesis when presented in isolation or in combination. ${ }^{30,40,41}$ When these cues are presented in combination, surface patterning plays an important role and topography can have a stronger influence on cell behavior when presented with effective surface chemistries. $^{42,43}$

In vertebrate and invertebrate systems, the main requisites for forming hard tissue or biomineral structures are calcium phosphate and calcium carbonate, respectively, both of which are assembled in a variety of ways, generating an incredible amount of structural diversity. ${ }^{44-49}$ This juxtaposition of phosphate and carbonate is described as the "bone-shell divide". ${ }^{50}$ It is intriguing that mammalian cells respond to mineral on the shell side of the bone-shell divide, and this begs 

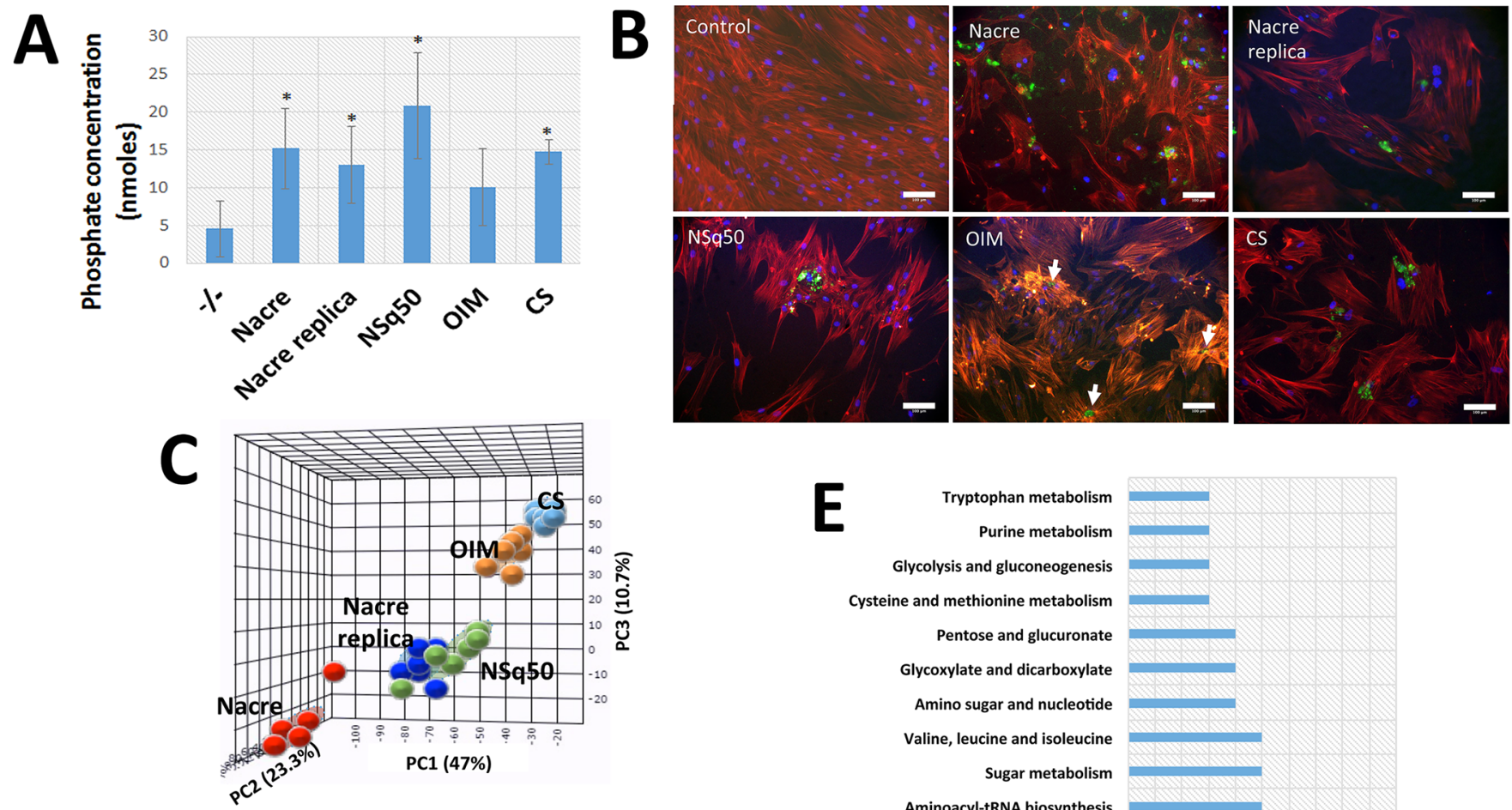

D

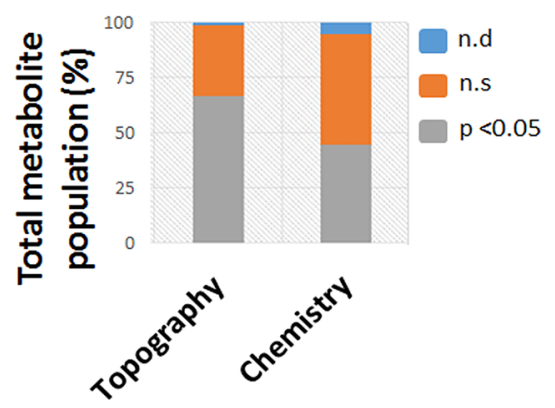

Figure 2. Osteogenic development of MSCs differentiated using nacre, nacre replica, NSq50, OIM, and CS. (A) Total phosphate concentrations measured from each sample set show elevated phosphate concentration in all five test groups compared to undifferentiated cells $(-/-)$, indicating the occurrence of mineralization processes in each group. Differentiated cells were subsequently stained for osteocalcin (green), which was observed on all of the test substrates apart from the planar controls (B). Metabolites obtained from MSCs cultured in each test group were assessed to profile cell behavior. (C) PCA indicates that, although all test groups undergo osteogenesis, the cells show distinct metabolic behaviors in the different scenarios. (D) Pairwise comparison between MSCs differentiated shows closer similarities in metabolism when differentiated using soluble ligands/chemistry (OIM and CS) than when using divergent surface topography (Nacre replica and NSq50), showing that using topography to induce differentiation has more diversified cell behavior when reacting to their microenvironment than when responding to chemical cues (n.d, not detected; n.s, not significant). (E) Metabolite masses that contribute to the loading plots used for PCA analysis (explaining the variances between groups) were mapped to known metabolic pathways giving information on which pathways are altered between groups. Error bars in (A) denote standard deviations from the mean; * indicates statistical significance compared to the control $(p<0.05)$ calculated using the Kruskal-Wallis test, followed by Dunn comparison, $n=6$. Fluorescently stained cells in (B) were also stained for cell nucleus (blue) and f-actin (red). Scale bar, $100 \mu \mathrm{m}$.

questions such as which feature of nacre elicits this response, and in transcending the bone-shell divide, do MSCs produce bone of similar or superior characteristics to that induced by other means? Addressing these questions has important implications in tissue engineering and biomaterial applications, especially with regards to orthopedic applications where critical sized defects in trauma and reconstructive surgery demand large areas of intact bone usually acquired by creating a secondary injury site. ${ }^{51}$

By isolating the topographical features of nacre from its inherent chemistry, we show that the osteoinductive properties of nacre arise from the patterning of the surface presented to MSCs. Importantly, separating nacre topography from its inherent chemistry enhances the osteogenic response. In this report we dissect out the contribution of topography to nacre bioactivity.

\section{RESULTS}

Surface Topography of Pinctada maxima Promotes in Vitro Osteogenesis of MSCs. The topographical features of nacre from Pinctada maxima (Figure 1A, D) were replicated on the polymer polycaprolactone (PCL) (Figure 1E) using an inverse pattern of the shell cast in polydimethylsiloxane (PDMS). Three-dimensional (3D) stereo scanning electron microscopy (SEM) was used to image the surface features of both nacre and its PCL replica. Stereo SEM images and digital 


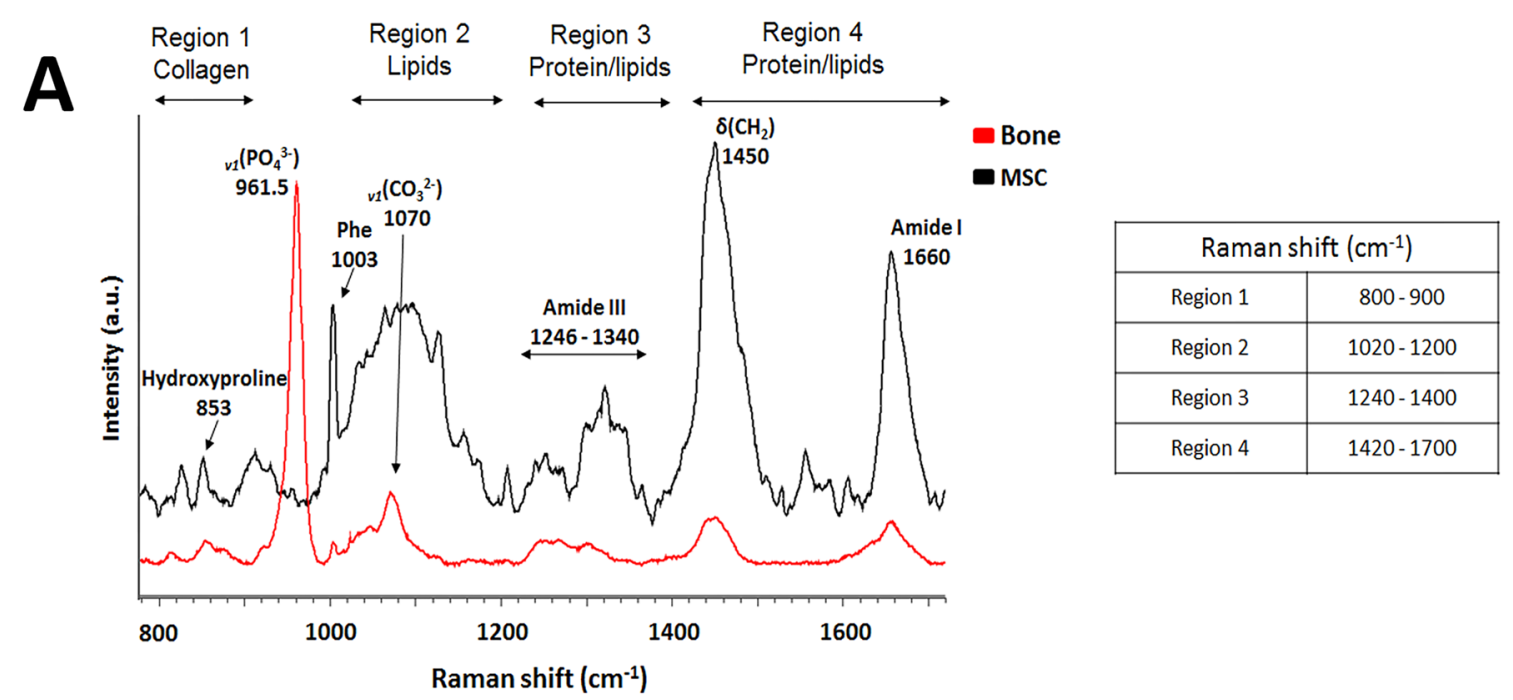

B
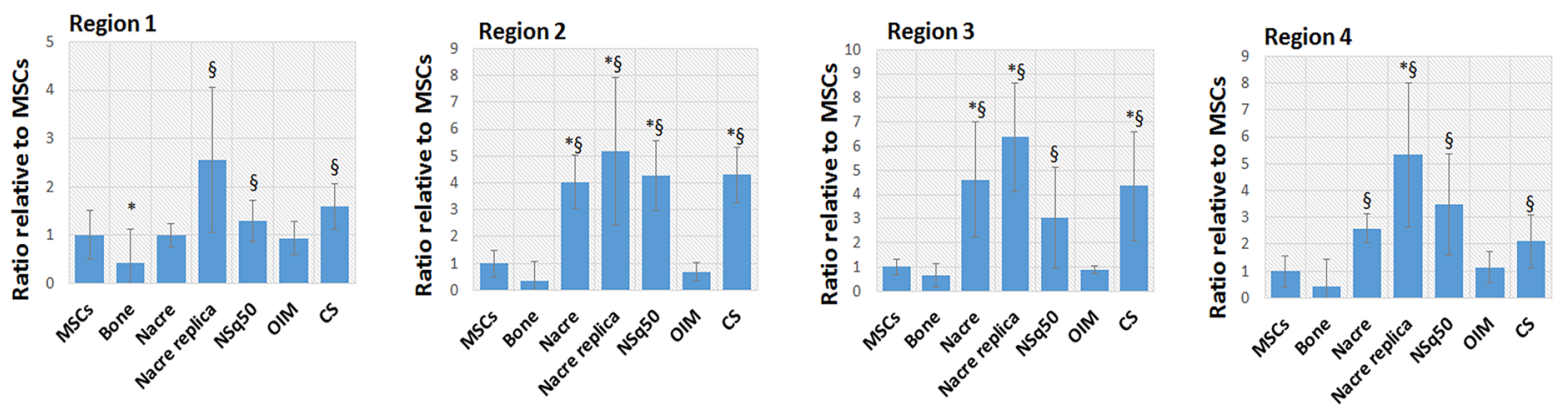

Figure 3. Raman spectral analyses of bone and cell matrix components of MSCs in response to nacre, nacre replica, NSq50, OIM, and CS. (A) Raman spectra of bone and undifferentiated MSCs describing regions used to assess differences in cell matrix features in (B) as they undergo topographically (nacre replica and NSq50), chemically (OIM and CS) and nacre-induced osteogenesis. Each region showed significant difference from the controls (MSCs and bone), suggesting that there are distinct differences between cellular lipid and protein content. Error bars in (B) denote standard deviations from the mean; * and $\S$ indicate statistical significance compared to the MSCs and bone, respectively, $(p<0.05)$ calculated using the Kruskal-Wallis test followed by Dunn comparison; $n=18$.

elevation modeling were used to quantify the surface roughness of nacre and its PCL replica (Figure 1D, E). Mean surface roughness measurements $(n=6)$ of nacre and the nacre replica surface averaged at $221.8 \pm 19 \mathrm{~nm}$ and $235.1 \pm 47.9 \mathrm{~nm}$, respectively, showing no significant difference between the original and replica surfaces (Figure 1B). This high fidelity of the replica of nacre topography replica confirms good pattern transfer.

PCL replicas were used for cell culture and assessed for gene transcription levels of typical mesenchyme lineages in the MSCs (planar PCL substrates were used as a negative control). Mesenchyme markers used to determine whether MSCs cultured on the nacre replica undergo differentiation were PPAR- $\gamma$ for adipogenesis, MyoD for myogenesis, SOX-9 for chondrogenesis, and osteopontin (OPN) for osteogenesis. Gene expression $(n=6)$ was quantified after 2 and 5 weeks in culture (Figure 1C). At 2 weeks, no activity was observed for PPAR- $\gamma$ and SOX-9 compared to the planar substrate. However, an increase in MyoD and OPN expression was noted at this time point. MyoD expression was not sustained at 5 weeks, and only OPN showed a time dependent increase in gene expression, suggesting that the MSCs had primarily undergone osteogenic development (Figure 1B).

Elevated gene expression of three additional osteogenic markers, osteocalcin ( $\mathrm{OCN})$, osteonectin ( $\mathrm{ONN})$, and osterix (OSX) (Figure S1), confirmed osteogenic development.
Immunofluorescent labeling of OPN in cultured cells on planar and nacre replica PCL is further confirmation of osteogenesis as cells cultured on the nacre replica stained positively for OPN, supporting the PCR findings (Figure 1F). These data demonstrate that the topographical feature has an important role in the osteoinductive capacity of nacre.

Osteogenic Phenotypes Are Altered According to Differentiation Persuasion. While increased expression of gene markers indicates osteogenic development, it does not provide any insight into the type of bone matrix being developed. To investigate this, we used a metabolomics-based approach to study the subphenotype adopted by the cells differentiating on the nacre replica substrate compared to those developing on nacre.

As there are a number of methods available to induce bone production in MSCs, we expanded the survey to include osteogenic differentiation by other physical and chemical cues. We included the near squared disordered pit array (NSq50$120 \mathrm{~nm}$ diameter pits with $100 \mathrm{~nm}$ depth and $300 \mathrm{~nm}$ centercenter spacing in a square lattice with a $\pm 50 \mathrm{~nm}$ offset from center position) substrate as used previously by Dalby et al., ${ }^{36}$ as an additional physical cue. The more commonly used osteogenic induction medium (OIM), constituting dexamethasone and ascorbate-2-phosphate, and cholesterol sulfate (CS) which has been shown to induce MSCs to undergo 
osteogenesis ${ }^{15,16,25,36}$ were included as additional chemical cues $(n=6)$.

Nacre, nacre replica, NSq50, OIM, and CS all successfully induced osteogenic differentiation of MSCs as indicated by the increase in total phosphate concentrations and positive fluorescent staining for osteocalcin after 3 weeks in culture (Figure 2A, B). Metabolomics data from all five scenarios were analyzed by principal component analysis (PCA) to identify differences in metabolomic response.

PCA shows neat clustering of the replicate samples for each scenario indicating good reproducibility. For each of the five scenarios, the metabolomic response was distinct, suggesting that each scenario had a different outcome on cellular subphenotype. Importantly, PCA analyses of metabolomics data separate out the response according to the manner by which the cells are differentiated, i.e., topography, chemistry, or combination (Figure 2C). Cells cultured on nacre were grouped separately from those differentiated on the nacre replica and the NSq50 substrate (topography). In turn, cells differentiated using these substrates also grouped separately from cells differentiated using OIM or CS (soluble chemistry).

Pairwise comparisons between the topographic substrates (nacre replica and NSq50) and chemically induced (OIM and CS) MSCs indicate that metabolomic response to these chemical cues is more similar to each other than the responses to the physical cues (nacre replica and NSq50) (Figure 2D). Of the total number of metabolites detected, $44 \%$ were significantly different from each other from MSCs differentiated using CS and OIM, while the difference is $67 \%$ from cells responding to topographic cues of nacre replica and NSq50 (Figure 2D). It is likely that the higher phenotypic similarity between MSCs that are chemically induced to undergo osteogenesis is due to the fact that OIM and CS are corticosteroids (synthetic dexamethasone and the naturally occurring cholesterol sulfate), which act by recruiting a common signaling pathway $(\mathrm{TGF} \beta) .^{22,38,52,53}$

An estimate of how much a metabolite contributes to the PC can be determined from the data loadings (Figure S3), as such, metabolites that contribute to the observed differences between sample sets can be identified. Metabolites were collated from the loading plots of the first three components and mapped to known metabolic pathways (Figure $2 \mathrm{E}$ ). ${ }^{54}$ The largest number of matched hits was for ascorbate and aldarate metabolism, phenylalanine, linoleic, and arginine, and proline metabolism. Notable contributions came from metabolites attributed to ascorbate and proline metabolism, suggesting variation in collagen production and thus differences in cell matrix features. ${ }^{55-58}$ Although ascorbate is instrumental in collagen production, it is expected that the variance observed with ascorbate metabolism has been somewhat biased by the inclusion of ascorbate-2-phosphate as a component of the OIM culture media. Linoleic acid metabolism, which contributes to the differences noted between sample types, is known to play an important role in bone development ${ }^{59-61}$ as well as acting as precursor for a class of broad range cell membrane signaling molecules (eicosanoids), inferring significant differences in cellular regulation. ${ }^{60}$

Irrespective of the differences in metabolic response, all five scenarios induced osteogenesis in the MSCs, suggesting that all scenarios are likely to produce a distinct type of bone tissue as a result of separate intracellular processes adopted. To investigate this, analysis of the resultant bone tissue was performed using Raman spectroscopy.
Assessment of Bone Properties Produced by MSCs Differentiated Using Physical and Chemical Cues. The Raman spectra of undifferentiated MSCs do not show any evidence of $\nu_{1} \mathrm{PO}_{4}{ }^{3-}$ symmetric stretching at $959 \mathrm{~cm}^{-1}$ (Figure $3 \mathrm{~A})$. The Raman spectra of all samples are dominated with protein features inclusive of skeletal $\mathrm{C}-\mathrm{C}$ stretch at $936 \mathrm{~cm}^{-1}$, amide III band at $1240 \mathrm{~cm}^{-1}$, amide band I at $1660 \mathrm{~cm}^{-1}$, and $\mathrm{CH}_{2}$ deformation at $1440 \mathrm{~cm}^{-1}$ (Figures 3A and S4) which are also used to identify cell organic and bone content (Table 3 ). Raman shifts indicative of lipids and phospholipid content are also observed at $1575,1065,1127$, and $1300 \mathrm{~cm}^{-1}$.

Spectral features describing the cellular matrix were different in each of the five induction scenarios $(n=6$ per group) (Figure S4). These features are also used to describe the quality of the bone tissue ${ }^{62,63}$ that is ultimately formed such as the mineral/matrix ratio, so analyses to describe the matrix features were carried out by sectioning the Raman shift into four main regions, each describing a set of known band assignments for the matrix component (Figure 3A, B). The area under the curve (AUC) for each section was used as, in some cases, poor spectral resolution, and overlapping of some bands makes it difficult to accurately isolate individual Raman shifts. As expected, the AUC overall for mature bone was less than that measured for MSCs indicative of the cell samples constituting higher protein and glycoprotein content than bone itself.

In agreement with other studies, ${ }^{62}$ with the exception of the presence of $\nu_{1}\left(\mathrm{PO}_{4}{ }^{3-}\right)$ stretch at $959 \mathrm{~cm}^{-1}$, no significant spectral changes to the matrix properties were observed when compared to undifferentiated cells (Figures 3 and S4).

Region 1 constitutes collagen proline and hydroxyproline species at 853,872 , and $920 \mathrm{~cm}^{-1}$ and is therefore indicative of changes that occur in collagen production. All samples showed a significant difference from mature bone in this region indicative of the much higher cell populations and organic material within the cell culture systems than is found in the bone tissue. Cells cultured on the nacre replica substrate showed the most significant change for this region, which is mainly dominated by the hydroxyl proline peak at $853 \mathrm{~cm}^{-1}$ (Figure 3B).

Region 2 typically describes lipid and proteoglycan content, $\nu_{1}\left(\mathrm{CO}_{3}{ }^{2-}\right), \nu_{3}\left(\mathrm{PO}_{4}{ }^{3-}\right)$, as well as collagen and hydroxyproline. ${ }^{64-69}$ The topographical substrates, CS and nacre, showed an increase in peak areas compared to both control sample sets. The dominant features within this region were the peaks at $1060 \mathrm{~cm}^{-1}$ (proteoglycan) and $1127 \mathrm{~cm}^{-1}$ (phospholipids) for NSq50, CS, and nacre. In the nacre replica, the peak at 1127 $\mathrm{cm}^{-1}$ dominates, but a peak at $1060 \mathrm{~cm}^{-1}$ is also detectable (Figure S4). In nacre, the carbonate peak at $1086 \mathrm{~cm}^{-1}$, which characteristically defines the nacre shell, is also sometimes present and very prominent within this region indicating that nacre itself is at times assimilated into the bone nodule (Figure S5). The lipid shift between 1060 and $1200 \mathrm{~cm}^{-1}$ is different in each scenario. In some cases the lipid shift overlaps the $\mathrm{CO}_{3}{ }^{2-}$ stretch indicative of B-type carbonate substitution in bone at $\approx 1070 \mathrm{~cm}^{-1}$ (Figure S4). This overlap removes the possibility of obtaining carbonate to phosphate ratios for all samples.

Region 3, which is the most statistically different between substrates, defines glycosaminoglycans, lipids, and protein content as described within the amide III band (Table $3)^{62,63,67,70,71}$ AUCs for nacre, nacre replica, NSq50, and CS are substantially increased. Region 3 is the most spectrally different for CS and nacre replica. The amide III envelope, in most cases, is not easily resolved spectrally, and this is also the 


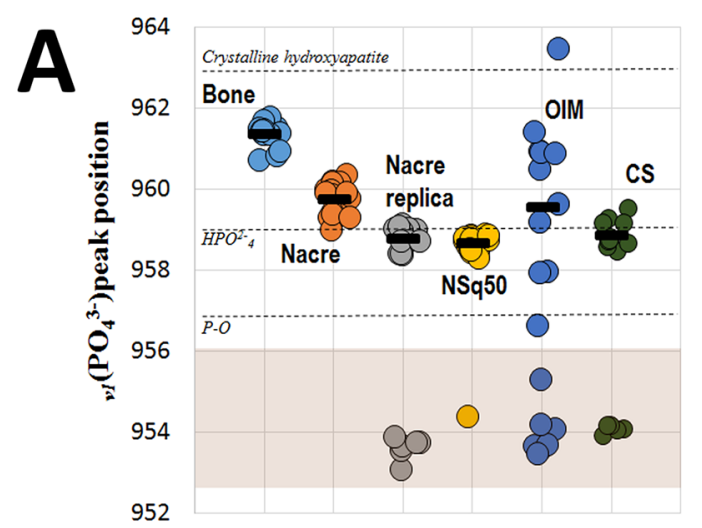

\begin{tabular}{|c|c|c|c|}
\hline & \multicolumn{2}{|c|}{ Phosphate } & \multirow{2}{*}{$\begin{array}{c}\text { Mineral to } \\
\text { Matrix } \\
\text { ratio }\end{array}$} \\
\hline & Peak position & FWHM $\left(\mathrm{cm}^{-1}\right)$ & \\
\hline Bone & $961.3 \pm 0.3$ & $16.3 \pm 0.2$ & $11.4 \pm 4.8$ \\
\hline Nacre & $959.7 \pm 0.4$ & $21.0 \pm 1.1^{*}$ & $5.90 \pm 3.3$ \\
\hline Nacre replica & $958.8 \pm 2.5^{*}$ & $7.6 \pm 0.7$ & $1.75 \pm 0.6^{*}$ \\
\hline NSq50 & $958.6 \pm 1.0^{*}$ & $12.4 \pm 6.3$ & $2.85 \pm 1.0 *$ \\
\hline OIM & $959.5 \pm 2.3$ & $34.6 \pm 10.1^{*}$ & $1.10 \pm 0.1^{*}$ \\
\hline CS & $958.8 \pm 2.3^{*}$ & $17.0 \pm 0.6$ & $1.25 \pm 0.3^{*}$ \\
\hline
\end{tabular}

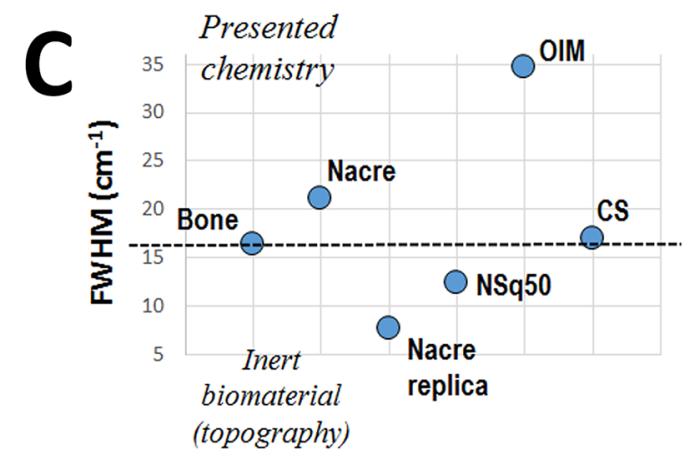

Figure 4. Raman spectral analyses of bone nodules formed by MSCs in response to nacre, nacre replica, NSq50, OIM, and CS. (A) Plot showing the distribution of $\nu_{1}\left(\mathrm{PO}_{4}{ }^{3-}\right)\left(952-964 \mathrm{~cm}^{-1}\right)$ as detected within each group showing the presence of nascent (shaded region) and more mature species. (B) Table of the peak position of $\nu_{1}\left(\mathrm{PO}_{4}{ }^{3-}\right)$ and full width half-maximum (fwhm $\left.\mathrm{cm}^{-1}\right)$ of this Raman shift and mineral:matrix ratio (measuring bone mineral abundance relative to cell matrix); * indicates statistical significance compared to bone $(p<$ 0.05) calculated using the Kruskal-Wallis test, followed by Dunn comparison. (C) The calculated fwhm of the $\nu_{1}\left(\mathrm{PO}_{4}{ }^{3-}\right) \mathrm{Raman}$ peak $\left(\mathrm{cm}^{-1}\right)$ (B) of each group is represented against a scale. Compared to native bone, tissues formed by cells differentiated using topographical induction were more crystalline than those that have direct influence from chemical induction agents.

case for the controls, NSq50, OIM, and nacre. CS, however, shows good resolution for peaks describing $\alpha$-helix protein structures at 1270 and $1340 \mathrm{~cm}^{-1}\left(\mathrm{CH}_{2} \mathrm{CH}_{2}\right.$ wag $)$. The latter peak dominates for nacre replica, while a smaller less resolved peak at $1240 \mathrm{~cm}^{-1}$ (amide III $\beta$-sheet) not present in CS can be seen. The lipid band $\delta(=\mathrm{CH})$ at $1300 \mathrm{~cm}^{-1}$ indicating formation of fresh bone $e^{67,72}$ is also prominent on the nacre replica.

Region 4 includes the protein $\mathrm{CH}_{2}$ deformation stretch at $1450 \mathrm{~cm}^{-1}$ and the amide I band, used as identifiers in this study (Table 3), and both are present in all sample sets. In addition to the $1660 \mathrm{~cm}^{-1}$ peak that defines amide I, on nacre a shoulder peak at $1690 \mathrm{~cm}^{-1}$ is detected which suggests the presence of immature collagen cross-links. ${ }^{73}$ The lipid peak at $1530 \mathrm{~cm}^{-1}$ is noted only on the nacre replica substrate. The analyses show that, although bone mineral is formed on all substrates, spectral features of the extracellular matrix show different lipid content and the presence of different secondary protein structures between the test samples.

The main definition of bone by Raman spectroscopy is the presence of a prominent phosphate peak $\nu_{1}\left(\mathrm{PO}_{4}{ }^{3-}\right)$ at $\approx 959$ $\mathrm{cm}^{-1}{ }^{63,67}$ Pure hydroxyapatite typically gives a peak at 964 $\mathrm{cm}^{-1}$. Shifts about this wavelength position define poorly crystalline hydroxyapatite ${ }^{63,74}$ as well as the presence of nascent or immature bone species through the buildup of phosphate links (Figure 4A). ${ }^{65,75}$ Analyses of the $\nu_{1}\left(\mathrm{PO}_{4}{ }^{3-}\right)$ peak produced by MSCs differentiated on all substrates showed that each had properties specific to the method used to differentiate the cells into osteoblasts (Figure 4A, B). In particular, samples collected from both topographical substrates (nacre replica and $\mathrm{NSq} 50$ ) and chemically induced cultures (CS and OIM) show the presence of the $\nu_{1}\left(\mathrm{PO}_{4}{ }^{3-}\right)$ peak at the significantly lower wavelength of $\approx 955 \mathrm{~cm}^{-1}$, indicating the presence of immature bone material and a continual turnover of bone mineral formation in these systems. ${ }^{66,75,76}$ As expected, no instances of these were found in the mature bone itself, signifying the lack of resident bone cells that would otherwise maintain active turnover within the tissue. Similarly, this was not noted for nacre suggesting that osteogenic development on nacre is more homogeneous than on the other substrates.

Statistical analyses were carried out using only the mature $(\approx$ $959 \mathrm{~cm}^{-1}$ ) phosphate position to ensure comparisons between similar $\nu_{1}\left(\mathrm{PO}_{4}{ }^{3-}\right)$ components in all scenarios using the same phosphate species. The full width at half-maximum (fwhm) of the phosphate peak indicates the degree of crystallinity of the bone tissue (Figure 4B, C). Short range disorders in crystallinity cause broadening of the $\nu_{1}\left(\mathrm{PO}_{4}{ }^{3-}\right)$ peak and decrease fwhm values. In contrast, low fwhm values indicate increased crystallinity of the bone. ${ }^{74}$ The measured crystallinity (fwhm) of native bone tissue was $16.3 \mathrm{~cm}^{-1}$, which is in good agreement with previous Raman studies on bone tissue. ${ }^{62,71,77}$ The fwhm values for the culture systems range from $7.6 \mathrm{~cm}^{-1}$ using the nacre replica to $34.6 \mathrm{~cm}^{-1}$ using osteogenic induction media (Figure 4B, C). The "immature" $\nu_{1}\left(\mathrm{PO}_{4}{ }^{3-}\right)$ species detected at $\approx 955 \mathrm{~cm}^{-1}$ typically measured as highly crystalline structures close to pure hydroxyapatite species $\left(6 \mathrm{~cm}^{-1}\right)$ which then become less crystalline as they mature and incorporate short-range disorder within the structure causing peak broad- 
ening. ${ }^{74}$ The exception to this was bone tissue formed by cells on the nacre replica substrate, which retained crystallinity (7.6 $\left.\mathrm{cm}^{-1}\right)$ irrespective of the position of the detected $\nu_{1}\left(\mathrm{PO}_{4}{ }^{3-}\right)$ peak. Bone produced by cells cultured on nacre or using OIM was significantly less crystalline than native bone. Peak measurements for nacre were less variable than for OIM $\left(21.0 \pm 1.1\right.$ and $34.6 \pm 10.1 \mathrm{~cm}^{-1}$ respectively), again indicating a more homogeneous bone tissue formation on nacre. While we report a fwhm value of $34.6 \mathrm{~cm}^{-1}$ in this study for MSC differentiation using OIM, it is noted that in the literature there is great variance and values have been reported from 16-92 $\mathrm{cm}^{-1}$. ${ }^{2,71,77}$ The reason for this variability is unknown and could be attributed to one or more variables such as slight differences in the media compositions, cell passage, or age/sex/ condition of the stem cell donor for example.

The mineral to matrix ratio was measured using peak intensities measured for the $\nu_{1}\left(\mathrm{PO}_{4}{ }^{3-}\right)$ peak at $\approx 959 \mathrm{~cm}^{-1}$ and the hydroxyproline peak at $\approx 853 \mathrm{~cm}^{-1}$ (Figure $4 \mathrm{~B}$ ). The ratio gives an insight into how much bone is present relative to the extracellular matrix. The highest ratio observed was for bone tissue at 11.4 phosphate:hydroxyproline, which is as expected. All other scenarios had between $1.1 \times$ and 5.9X more phosphate, which are comparable with other osteogenic cell culture observations. ${ }^{62,71,77-79}$ Bone tissue has the highest mineral:matrix ratio, followed by cells on the nacre substrate at 5.9, then NSq50, and nacre replica with ratios of 2.85 and 1.75 , respectively. Finally, chemically induced differentiation has ratios of 1.25 and 1.1 for CS and OIM respectively (Figure 4B).

\section{DISCUSSION}

When the topography of nacre is isolated from any chemical signal, topography alone is able to induce MSCs to undergo osteogenesis. Osteogenic development differs significantly between nacre and the topographical replica where the cells on the topography replica adopt separate metabolic function from those on nacre. Subsequently, differences in metabolism lead to formation of bone tissue that has significantly transformed extracellular matrix constituents and, most markedly, different tissue crystallization features where the cells on the topography maintain a higher crystalline characteristic than that of its nacreous counterpart, suggesting the formation of harder bone tissue. ${ }^{80}$ The fact that the mineral:matrix ratio produced on nacre replica is not as high as on nacre may result from the innate material properties of nacre which could be readily addressed in future replica construction. Importantly, the crystallinity of the mineral is higher in response to nacre replica than to nacre or to any of the other cues, with the lowest value for full width at halfmaximum (fwhm) of the Raman shift. These findings warn against the use of a single measure of mineral quality and instead recommend the use of multiple measures as employed here.

Inclusion of additional osteogenic culture systems, that is, the use of NSq50 topographies and cholesterol sulfate or the more widely used dexamethasone supplemented media (OIM), helped to further describe the osteogenic process. The absence of chemistry from the cell culture system by presenting nacre replica and $\mathrm{NSq} 50$ had the overall effect of producing lower fwhm values of the $\nu_{1}\left(\mathrm{PO}_{4}{ }^{3-}\right)$ symmetric stretch, suggesting that cells cultured on topography alone produced more crystalline bone than those presented with chemistry (Figure 4). The presence of a peak at $1086 \mathrm{~cm}^{-1}$ in bone nodules formed on the nacre substrate is also an interesting observation as it further supports previous studies that suggest assimilation of nacre into bone tissue structure, ${ }^{10,14}$ and this study shows that this can also be detected in vitro using Raman spectroscopy (Figure S5).

Naturally occurring bone tissue is a heterogeneous structure formed from differences in mineralization rates and constant remodelling of the extracellular matrix by bone cells inevitably leading to differences in mineral density, composition, and collagen content. $^{63,79,81}$ It is noteworthy to mention that assessments of bone tissue in vivo have reported that higher crystallinity may be associated with brittle bone, ${ }^{79,82}$ but this is also dependent on the interactions with the aforementioned properties. Studies by $\mathrm{Bi}$ et al. have shown that the mineral:matrix ratio when the proline or amide III Raman shift is used have a direct correlation with the mechanical properties of bone. ${ }^{83}$ The results thus predict that the less crystalline nodules obtained using chemical cues would be weaker bone than those formed on the topographies. From our data, we could predict that nacre, as a combination material, should have the highest strength of template new bone.

The ability of nacre topography to induce osteogenic development in stem cells is a characteristic that is advantageous in tissue engineering applications, as patterns can be transferred with high fidelity onto polymer substrates for implantation, which are time and cost effective as well as enabling manufacture on a large scale.

\section{CONCLUSIONS}

Although previous studies have revealed that nacre is an effective osteoinductive and osteointegrative material, this study shows that nacre topography alone is osetoinductive since MSCs are successfully differentiated along this lineage using only the nacre replica. We demonstrate that subtle differences in the nanoscale environment affect cell behavior and, in this case, with respect to bone mineralization, generates a significant effect on the quality of the tissue produced. By comparing bone formation obtained using a nacre topography replica to established methods for osteogenesis induced by topographic and chemical means, we were able to demonstrate that although osteogenic development of MSCs occurs in all systems, there are distinct differences in the cell activity that correlates with the type of stimulus used to induce differentiation. These differences subsequently affect the quality of the deposited bone mineral, illustrating that the topographical technique produces bone of better quality. This aspect could be incorporated into tissue engineering and biomaterial design for application in orthopedics and osteoarthritis research where bone enrichment is fundamental.

\section{METHODS/EXPERIMENTAL SECTION}

Cell Culture. Mesenchymal stem cells (purchased from Promocell $\mathrm{GmbH}$ (human, from bone marrow)) were expanded and cultured in standard culture media (DMEM (PAA Laboratories) supplemented with $10 \% \mathrm{v} / \mathrm{v}$ fetal bovine serum (FBS) and $2 \% \mathrm{v} / \mathrm{v}$ antibiotic mix $(60 \% \mathrm{v} / \mathrm{v}$ L-glutamine, $35 \% \mathrm{v} / \mathrm{v}$ penicillin streptomysin, and $5 \% \mathrm{v} / \mathrm{v}$ ampotericin B)) on the appropriate substrate used for normalization or as negative controls. These were planar polycaprolactone (PCL), polycarbonate, or tissue culture well plastic. Cells used for Raman spectroscopy were plated at a density of $2 \times 10^{5}$, and cells used in all other experiments were done using approximately $1 \times 10^{4}$. Culture plates were incubated under humidified atmosphere of $5 \% \mathrm{CO}_{2}$ at 37 ${ }^{\circ} \mathrm{C}$, and the media were replaced twice weekly for the duration of the experiments. 
Osteogenic Differentiation. Mesenchymal stem cells were induced into undergoing osteogenic development using a number of methodologies. These can be class broadly into three groups (Table $1)$

Table 1. Differentiation Techniques Used for Osteoinduction of MSCs

\begin{tabular}{|c|c|}
\hline differentiation cue & material \\
\hline negative control & planar/unpatterned PCL \\
\hline soluble chemistry & osteogenic induction media \\
\hline & cholesterol sulfate \\
\hline topography & nacre surface replica \\
\hline & near square disordered $(\mathrm{NSq} 50)$ pattern \\
\hline combination & nacre shell \\
\hline
\end{tabular}

Soluble Chemistry. MSCs were induced to osteogenesis in this manner using two separate cell culture supplements. The first, osteogenic induction media (OIM) was made as described and is used extensively in experiments by supplementing the cell culture media with $10 \mathrm{nM}$ dexamethasone and $100 \mu \mathrm{g} / \mathrm{mL}$ ascorbate-2-phosphate. $^{23,25}$ The second makes use of the cell culture medium supplemented with $1 \mu \mathrm{M}$ cholesterol sulfate as reported previously. ${ }^{53}$

Substrate Topography. Electron beam lithography (EBL) was used to fabricate nanoscale near disordered (NSq50) substrates comprising arrays of $120 \mathrm{~nm}$ diameter pits of $100 \mathrm{~nm}$ depth and average $300 \mathrm{~nm}$ pitch in a square arrangement. Random displacement, of up to \pm 50 $\mathrm{nm}$ in $\mathrm{X}$ and $\mathrm{Y}$ from the highly ordered arrays, was introduced while maintaining an average $300 \mathrm{~nm}$ pitch, as previously described by Dalby et al. $^{36}$

Nacre replica: Inverse patterns were fabricated in polydimethylsiloxane (PDMS stamps) by pouring a 1:10 PDMS mixture (degassed prior to use) neatly onto the shell and curing at $60^{\circ} \mathrm{C}$ for $1 \mathrm{~h}$. Replicas were then subsequently made using polycaprolactone (PCL) beads which had been washed in methanol and allowed to air-dry. These were melted at $80^{\circ} \mathrm{C}$ on a hot plate, and the PDMS stamp was pressed into the molten PCL. Samples were then removed and allowed to cool to room temperature, thus allowing the PCL to solidify. The stamp was then peeled away from the PCL generating a positive replica of the nacre surface. Planar or unpatterned control surfaces were made by compressing molten PCL between two clean unpatterned glass slides and cooled at room temperature to solidify before removing from the glass slide.

Combination Material. Nacre was obtained from the pearl oyster Pinctada maxima kindly contributed by Patrick Moase and Clipper Pearls Pty Ltd. Shells were cut to approximately $2 \mathrm{~cm}^{2}$ sizes for cell culture. Substrates were sonicated for $10 \mathrm{~min}$ and washed in $70 \%$ ethanol prior to cell seeding.

Scanning Electron Microscopy and Digital Elevation Modeling. Fractured shell sections and their PCL replicate sections were fixed to SEM stubs and coated with a thin layer of carbon prior to imaging. Pattern fidelity of replica substrates was assessed using SEM, taking two images at 0 and $5^{\circ}$ stage tilt. From these, 3D images were created using digital elevation modeling (DEM). SEM imaging and DEM were carried out on a Quanta 200 (FEI) scanning electron microscope and Alicona Mex 5.1 software in the Imaging, Spectroscopy and Analysis Centre (ISAAC) at the School of Geographical and Earth Sciences at the University of Glasgow. Surface roughness was calculated as the deviation from the averaged baseline.

Phosphate Quantification Assay. Phosphate quantification was performed using an assay kit from Abcam. The method was slightly modified from the manufacturers' protocol and is summarized below. Samples used for Raman spectroscopy were also used to perform this assay. Twenty $\mu \mathrm{L}$ for each test sample was aliquoted into a 96-well plate, and $3 \mu \mathrm{L}$ of the phosphate reagent added to each well. Samples were then incubated at room temperature for $30 \mathrm{~min}$, and the absorption was read at a wavelength of $650 \mathrm{~nm}$ using a Nanodrop 2000c spectrometer (Thermo Scientific, UK). A standard curve was made using a phosphate standard from which total phosphate content was calculated. Samples that were over the linear range of the standard curve were subsequently diluted to obtain readings that fall into the linear range.

RT-PCR. Cells cultured for 2 and 5 weeks had RNA retrieved using RNeasy micro kit (Qiagen), and the protocol was carried out as per manufacturers' instructions. Reverse transcription to obtain cDNA was done using Quantitech reverse transcription kit (Qiagen) for all samples, also according to the manufacturers' protocol. Amplification by qRT-PCR was done using human specific primers (Eurofins MWG Operon) detailed in Table 2. PCR was carried out using a 7500 real

Table 2. Real Time PCR Primers Used To Quantify mRNA Expression from Human Genes

\begin{tabular}{|c|c|c|}
\hline gene & & \\
\hline \multirow[t]{2}{*}{ PPAR- $\gamma$} & forward & 5'-TGT GAA GCC CAT TGA AGA CA-3' \\
\hline & reverse & 5'-CTG CAG TAG CTG CAC GTG TT-3' \\
\hline \multirow{2}{*}{ MyoD } & forward & $5^{\prime}$-CAC TAC AGC GGC GAC TCC-3' \\
\hline & reverse & 5'-TAG GCG CCT TCG TAG CAG-3' \\
\hline \multirow[t]{2}{*}{ SOX-9 } & forward & 5'-AGA CAG CCC CCT ATC GAC TT-3' \\
\hline & reverse & 5'-CGG CAG GTA CTG GTC AAA CT-3' \\
\hline \multirow[t]{2}{*}{ OPN } & forward & 5'-AGC TGG ATG ACC AGA GTG CT- $3^{\prime}$ \\
\hline & reverse & $5^{\prime}$-TGA AAT TCA TGG CTG TGG AA $-3^{\prime}$ \\
\hline \multirow[t]{2}{*}{ OCN } & forward & 5'-CAG CGA GGT AGT GAA GAG ACC-3' \\
\hline & reverse & 5'-TCT GGA GTT TAT TTG GGA GCA G-3' \\
\hline \multirow[t]{2}{*}{ Osx } & forward & $5^{\prime}$-GCT TAT CCA GCC CCC TTT AC $-3^{\prime}$ \\
\hline & reverse & $5^{\prime}$-CAC TGG GCA GAC AGT CAG AA $-3^{\prime}$ \\
\hline \multirow[t]{2}{*}{ GAPDH } & forward & 5'-ACC CAG AAG ACT GTG GAT GG-3' \\
\hline & reverse & 5'-TTC TAG ACG GCA GGT CAG GT-3' \\
\hline
\end{tabular}

time PCR system and software (Applied Biosystems). Samples had a total reaction volume of $20 \mu \mathrm{L}$ containing $2 \mu \mathrm{L}$ of diluted cDNA, where each reverse and forward primer at a final concentration of 100 $\mu \mathrm{M}$ and analyzed using SYBR green chemistry (Qiagen). For PCR amplification samples were held at $50{ }^{\circ} \mathrm{C}$ for 2 min, then $95{ }^{\circ} \mathrm{C}$ for 10 min, and then amplified using $95^{\circ} \mathrm{C}$ for $15 \mathrm{~s}$ and $60{ }^{\circ} \mathrm{C}$ for $1 \mathrm{~min}$ for 40 cycles. The specificity of the PCR amplification was checked with a heat dissociation curve (measured between 60 and $95^{\circ} \mathrm{C}$ ) subsequent to the final PCR cycle. Gene expression levels were standardized using GAPDH as an internal control. Quantification analysis was performed using the comparative $\Delta \Delta \mathrm{Ct}$ method $^{84}$ and gene expression expressed as fold change relative to the control sample.

Samples were assayed in quadruplicate, and gene expression was expressed as mean \pm SEM.

Immunofluorescent Microscopy. Glass coverslip and PCL substrates used for fluorescence imaging were rinsed once in PBS and fixed at $37{ }^{\circ} \mathrm{C}$ for $15 \mathrm{~min}$. They were then permeabilized and blocked using $1 \%$ BSA in PBS. Following this, cells were then incubated at $37{ }^{\circ} \mathrm{C}$ for $1 \mathrm{~h}$ with rhodamine-conjugated phalloidin and the required primary antibody. After $1 \mathrm{~h}$, cells were washed three times for 5 min with $0.5 \%$ tween in PBS (cells cultured within substrates were washed for $15 \mathrm{~min}$ to ensure removal of excess antibody from the hydrogels) and incubated for $1 \mathrm{~h}$ at $37{ }^{\circ} \mathrm{C}$ with the corresponding secondary antibody. Cells were again washed three times with $0.5 \%$ tween in PBS as required, incubated at $4{ }^{\circ} \mathrm{C}$ for 30 min with streptavidin conjugated FITC, and washed again as before after the incubation time elapsed. Samples were then mounted onto a drop of Vectashield-DAPI (a glycerol-based mounting medium for preserving fluorescence containing DAPI for nucleic acid staining) on a microscope slide. For biomaterial substrates, Vectashield-DAPI was diluted in PBS and added to the well plates. All samples were stored at $4{ }^{\circ} \mathrm{C}$ wrapped in foil to protect from photobleaching until ready for viewing under a microscope.

Cellular Metabolomics. Metabolite extraction from cells cultured in the five scenarios and control samples at 1 and 4 weeks were carried out on ice using ice cold chloroform:methanol:water $(1: 3: 1, \mathrm{v} / \mathrm{v})$ by agitating on a shaker for $1 \mathrm{~h}$ and then incubating at $4{ }^{\circ} \mathrm{C}$ for 1 and 4 weeks. Samples were centrifuged to sediment debris. An aliquot (10 
$\mu \mathrm{L})$ of the supernatant was injected into the LC-MS system. The LC separation was achieved using hydrophilic interaction chromatography with a ZIC-pHILIC $150 \mathrm{~mm} \times 4.6 \mathrm{~mm}, 5 \mu \mathrm{m}$ column (Merck Sequant), operated by an UltiMate 3000 RSLC liquid chromatography system (Thermo Fisher Scientific, UK). The LC mobile phase comprised $20 \mathrm{mM}$ ammonium carbonate in water (A) and acetonitrile (B). A linear gradient of the mobile phase was run at a linear gradient for $15 \mathrm{~min}$ from $20 \%$ to $80 \% \mathrm{~A}$, maintained at $5 \% \mathrm{~A}$ for $4 \mathrm{~min}$, and then re-equilibrated to $20 \%$ A. An Orbitrap Q-Exactive (Thermo Fisher Scientific, Hemel Hempstead, UK) was used for mass spectrometric detection within the mass range $\mathrm{m} / \mathrm{z} 70-1050$ in polarity switching mode. Chromatographic peak selection and metabolite identification used our in-house XCMS/MzMatch/ IDEOM pipeline. ${ }^{85,86}$ Measured peak intensities by LC-MS were normalized against protein content as measured using the Bradford assay as detailed previously. ${ }^{87}$ Metabolite identification used a set of standards to define mass and chromatographic retention times. Putative metabolites were also identified on this basis by using predicted retention times as described by Creek et al ${ }^{88}$ Peak intensities were normalized to total protein content of each sample set $(n=6)$, and ratios of each metabolite mass were calculated relative to undifferentiated MSCs as a basal control. Ratios were then used for subsequent statistical analyses.

Raman Spectroscopy. Due to the method used to induce some of the MSCs to undergo osteogenesis (i.e., use of patterned substrates and nacre in particular), cells attached to their substrates could not be analyzed directly using the Raman spectrometer. Alternatively, the cells and their ECM were removed from each substrate by gently scraping them away and allowing dispersion into the culture media. This was then centrifuged, the supernatant was removed, and the pellet resuspended in $50 \mu \mathrm{L}$ of a $4 \%$ fixative solution. Five $\mu \mathrm{L}$ of the sample was then spotted onto a $\mathrm{CaF}_{2}$ substrate, allowed to air-dry, and then used to obtain Raman spectra. Spectra were obtained after cells had been differentiating in culture for 3 weeks using a Renishaw inVIA spectrometer connected to a Leica microscope and using a $785 \mathrm{~nm}$ laser. The laser beam was focused through a $100 \times$ lens objective, and all samples were collected at this magnification. Spectra were collected over the Raman wavelength of $700-1750 \mathrm{~cm}^{-1}$ using a $30 \mathrm{~s}$ exposure at $50 \%$ laser for each data point. A total of 18 replicates were measured. Data were normalized using a multipoint baseline correction, and curve fitting was applied using the WiRE 4.0 software. Spectra were inspected for the presence of a number of diagnostic peaks which are typical of bone tissue (Table 3). ${ }^{63,67}$ Values obtained

\section{Table 3. Raman Shifts to Identify Bone Spectra}

\begin{tabular}{|c|c|}
\hline peak assignment & position, Raman shift $\left(\mathrm{cm}^{-1}\right)$ \\
\hline proline/hydroxyproline & 853 \\
\hline$\nu_{1} \mathrm{PO}^{3-}{ }_{4}$ & $950-964$ \\
\hline Phe & 1003 \\
\hline$\nu_{3} \mathrm{PO}_{4}^{3-}$ & $1035-1048$ \\
\hline$\nu_{1} \mathrm{CO}_{3}^{2-}$ & $1065-1070$ \\
\hline hydroxyproline, Tyr & 1200 \\
\hline amide III $\beta$-sheet & 1240 \\
\hline amide III $\alpha$-helix & 1260 \\
\hline$\delta(=\mathrm{CH})$ & $1293-1305$ \\
\hline amide III $\mathrm{CH}_{2} \mathrm{CH}_{2}$ wag & 1344 \\
\hline$\delta\left(\mathrm{CH}_{2}\right)$ & 1450 \\
\hline amide I & $1616-1720$ \\
\hline
\end{tabular}

for mineral/matrix ratios were ascertained using the intensities from the phosphate and hydroxyproline band, as intensity readings at specific wavelengths are less prone to correction errors. Comparisons between the protein and lipid profiles however were carried out using the area under the curve or peak area, as these take into account contributions from a wide range.

Statistical Analysis. Multivariate principal component analysis was carried out using Metaboanalyst 3.0. ${ }^{89}$ Univariate analysis-one way ANOVA followed by Tukey's posthoc and two tailed pairwise comparisons were carried out using GraphPad Prism software (version 6.03). Statistical analyses were carried out using at least four replicate samples.

\section{ASSOCIATED CONTENT}

\section{S Supporting Information}

The Supporting Information is available free of charge on the ACS Publications website at DOI: 10.1021/acsnano.7b01044.

Additional details and data. Raw data available from http://dx.doi.org/10.5525/gla.researchdata.345 (PDF)

\section{AUTHOR INFORMATION}

\section{Corresponding Authors}

*E-mail: maggie.cusack@stir.ac.uk.

*E-mail: Matthew.Dalby@glasgow.ac.uk.

ORCID 우

Nikolaj Gadegaard: 0000-0002-3396-846X

Maggie Cusack: 0000-0003-0145-1180

Notes

The authors declare no competing financial interest.

\section{ACKNOWLEDGMENTS}

This work was funded by the Medical Research Council (MRC) grant MR/K011278/1 'Stem cell metabolomics for bone therapies and tissue engineering'. We would like to thank Bernie Degnan and Carmel McDougall of the University of Queensland and Patrick Moase of Clipper Pearls Pty Ltd for provision of the Pinctada maxima shells.

\section{REFERENCES}

(1) Jackson, A. P.; Vincent, J. F. V.; Turner, R. M. The Mechanical Design of Nacre. Proc. R. Soc. London, Ser. B 1988, 234, 415-440.

(2) Kono, M.; Hayashi, N.; Samata, T. Molecular Mechanism of the Nacreous Layer Formation in Pinctada maxima. Biochem. Biophys. Res. Commun. 2000, 269, 213-218.

(3) Almeida, M. J.; Milet, C.; Peduzzi, J.; Pereira, L.; Haigle, J.; Berthelemy, M.; Lopez, E. Effect of Water-Soluble Matrix Fraction Extracted From the Nacre of Pinctada maxima on the Alkaline Phosphatase Activity of Cultured Fibroblasts. J. Exp. Zool. 2000, 288, 327-334.

(4) Gong, N.; Ma, Z.; Li, Q.; Li, Q.; Yan, Z.; Xie, L.; Zhang, R. Characterization of Calcium Deposition and Shell Matrix Protein Secretion in Primary Mantle Tissue Culture from the Marine Pearl Oyster Pinctada fucata. Mar. Biotechnol. 2008, 10, 457-465.

(5) Mann, S. Molecular Recognition in Biomineralization. Nature 1988, 332, 119-124.

(6) Weiner, S. Mollusk Shell Formation - Isolation of 2 Organic Matrix Proteins Associated with Calcite Deposition in the Bivalve Mytilus californianus. Biochemistry 1983, 22, 4139-4145.

(7) Weiner, S.; Addadi, L. Design Strategies in Mineralized Biological Materials. J. Mater. Chem. 1997, 7, 689-702.

(8) Marin, F.; Pokroy, B.; Luquet, G.; Layrolle, P.; De Groot, K. Protein Mapping of Calcium Carbonate Biominerals by Immunogold. Biomaterials 2007, 28, 2368-2377.

(9) Westbroek, P.; Marin, F. A Marriage of Bone and Nacre. Nature 1998, 392, 861-862.

(10) Atlan, G.; Balmain, N.; Berland, S.; Vidal, B.; Lopez, E. Reconstruction of Human Maxillary Defects with Nacre Powder: Histological Evidence for Bone Regeneration. C. R. Acad. Sci., Ser. III 1997, 320, 253-258.

(11) Atlan, G.; Delattre, O.; Berland, S.; LeFaou, A.; Nabias, G.; Cot, D.; Lopez, E. Interface Between Bone and Nacre Implants in Sheep. Biomaterials 1999, 20, 1017-1022. 
(12) Lamghari, M.; Almeida, M. J.; Berland, S.; Huet, H.; Laurent, A.; Milet, C.; Lopez, E. Stimulation of Bone Marrow Cells and Bone Formation by Nacre: in vivo and in vitro Studies. Bone 1999, 25, 91S94S.

(13) Pascaretti-Grizon, F.; Libouban, H.; Camprasse, G.; Camprasse, S.; Mallet, R.; Chappard, D. The Interface Between Nacre and Bone after Implantation in the Sheep: a Nanotomographic and Raman Study. J. Raman Spectrosc. 2014, 45, 558-564.

(14) Lopez, E.; Atlan, G.; Berland, S.; Balmain, N. Bone Regeneration Induced by Nacre in Human Maxillary Bone Defect. Bone (N. Y., NY, U. S.) 1997, 20, 107S-107S.

(15) Flausse, A.; Henrionnet, C.; Dossot, M.; Dumas, D.; Hupont, S.; Pinzano, A.; Mainard, D.; Galois, L.; Magdalou, J.; Lopez, E.; Gillet, P.; Rousseau, M. Osteogenic Differentiation of Human Bone Marrow Mesenchymal Stem Cells in Hydrogel Containing Nacre Powder. J. Biomed. Mater. Res., Part A 2013, 101, 3211-3218.

(16) Green, D. W.; Kwon, H.-J.; Jung, H.-S. Osteogenic Potency of Nacre on Human Mesenchymal Stem Cells. Mol. Cells 2015, 38, 267272.

(17) Lopez, E.; Vidal, B.; Berland, S.; Camprasse, S.; Camprasse, G.; Silve, C. Demonstration of the Capacity of Nacre to Induce BoneFormation by Human Osteoblasts Maintained in vitro. Tissue Cell 1992, 24, 667-679.

(18) Chen, J.-C.; Kung, J.-C.; Hsieh, C.-H.; Hou, M.-J.; Shih, C.-J.; Hung, C.-C. Mineralization and Osteoblast Cells Response of Nanograde Pearl Powders. J. Nanomater. 2013, 2013, 752863.

(19) Liu, Y.; Huang, Q.; Feng, Q. 3D Scaffold of PLLA/pearl and PLLA/Nacre Powder for Bone Regeneration. Biomed. Mater. 2013, 8, 065001.

(20) Rousseau, M.; Pereira-Mouries, L.; Almeida, M. J.; Milet, C.; Lopez, E. The Water-Soluble Matrix Fraction from the Nacre of Pinctada maxima Produces Earlier Mineralization of MC3T3-E1Mouse Pre-Osteoblasts. Comp. Biochem. Physiol., Part B: Biochem. Mol. Biol. 2003, 135, 1-7.

(21) Jaiswal, N.; Haynesworth, S. E.; Caplan, A. I.; Bruder, S. P. Osteogenic Differentiation of Purified, Culture-Expanded Human Mesenchymal Stem Cells in Vitro. J. Cell. Biochem. 1997, 64, 295-312.

(22) Kilian, K. A.; Bugarija, B.; Lahn, B. T.; Mrksich, M. Geometric Cues for Directing the Differentiation of Mesenchymal Stem Cells. Proc. Natl. Acad. Sci. U. S. A. 2010, 107, 4872-4877.

(23) Mirmalek-Sani, S.; Tare, R.; Morgan, S. M.; Roach, H.; Wilson, D.; Hanley, N.; Oreffo, R. C. Characterization And Multipotentiality of Human Fetal Femur-Derived Cells: Implications for Skeletal Tissue Regeneration. Stem Cells 2006, 24, 1042-1053.

(24) Peng, L. Y.; Jia, Z. Q.; Yin, X. H.; Zhang, X.; Liu, Y. A.; Chen, P.; Ma, K. T.; Zhou, C. Y. Comparative Analysis of Mesenchymal Stem Cells from Bone Marrow, Cartilage, and Adipose Tissue. Stem Cells Dev. 2008, 17, 761-773.

(25) Pittenger, M. F.; Mackay, A. M.; Beck, S. C.; Jaiswal, R. K.; Douglas, R.; Mosca, J. D.; Moorman, M. A.; Simonetti, D. W.; Craig, S.; Marshak, D. R. Multilineage Potential of Adult Human Mesenchymal Stem Cells. Science 1999, 284, 143-147.

(26) Kaur, G.; Wang, C.; Sun, J.; Wang, Q. The Synergistic Effects of Multivalent Ligand Display and Nanotopography on Osteogenic Differentiation of Rat Bone Marrow Stem Cells. Biomaterials 2010, 31, $5813-5824$

(27) Rowlands, A. S.; George, P. A.; Cooper-White, J. J. Directing Osteogenic and Myogenic Differentiation of MSCs: Interplay of Stiffness and Adhesive Ligand Presentation. Am. J. Physiol. 2008, 295, C1037-C1044.

(28) Allen, J. L.; Cooke, M. E.; Alliston, T. ECM Stiffness Primes the TGF Beta Pathway to Promote Chondrocyte Differentiation. Mol. Biol. Cell 2012, 23, 3731-3742.

(29) Discher, D. E.; Janmey, P.; Wang, Y. L. Tissue Cells Feel and Respond to the Stiffness of their Substrate. Science 2005, 310, 11391143.

(30) Discher, D. E.; Mooney, D. J.; Zandstra, P. W. Growth Factors, Matrices, and Forces Combine and Control Stem Cells. Science 2009, 324, 1673-1677.
(31) Engler, A. J.; Sen, S.; Sweeney, H. L.; Discher, D. E. Matrix Elasticity Directs Stem Cell Lineage Specification. Cell 2006, 126, 677-689.

(32) Raab, M.; Shin, J.-W.; Discher, D. E. Matrix Elasticity in Vitro Controls Muscle Stem Cell Fate. Stem Cell Res. Ther. 2010, 1, 38.

(33) Yang, C.; Tibbitt, M. W.; Basta, L.; Anseth, K. S. Mechanical Memory and Dosing Influence Stem Cell Fate. Nat. Mater. 2014, 13, 645-652.

(34) Young, J. L.; Engler, A. J. Hydrogels with Time-Dependent Material Properties Enhance Cardiomyocyte Differentiation. Biomaterials 2011, 32, 1002-1009.

(35) Brammer, K. S.; Choi, C.; Frandsen, C. J.; Oh, S.; Jin, S. Hydrophobic Nanopillars Initiate Mesenchymal Stem Cell Aggregation and Osteo-Differentiation. Acta Biomater. 2011, 7, 683-690.

(36) Dalby, M. J.; Gadegaard, N.; Tare, R.; Andar, A.; Riehle, M. O.; Herzyk, P.; Wilkinson, C. D. W.; Oreffo, R. O. C. The Control of Human Mesenchymal Cell Differentiation Using Nanoscale Symmetry and Disorder. Nat. Mater. 2007, 6, 997-1003.

(37) Dellatore, S. M.; Garcia, A. S.; Miller, W. M. Mimicking Stem Cell Niches to Increase Stem Cell Expansion. Curr. Opin. Biotechnol. 2008, 19, 534-540.

(38) Tsimbouri, P. M.; McMurray, R. J.; Burgess, K. V.; Alakpa, E. V.; Reynolds, P. M.; Murawski, K.; Kingham, E.; Oreffo, R. O. C.; Gadegaard, N.; Dalby, M. J. Using Nanotopography and Metabolomics to Identify Biochemical Effectors of Multipotency. ACS Nano 2012, 6, 10239-10249.

(39) Yang, J.; McNamara, L. E.; Gadegaard, N.; Alakpa, E. V.; Burgess, K. V.; Meek, R. M. D.; Dalby, M. J. Nanotopographical Induction of Osteogenesis through Adhesion, Bone Morphogenic Protein Cosignaling, and Regulation of MicroRNAs. ACS Nano 2014, 8, 9941-9953.

(40) Choi, J. S.; Harley, B. A. C. The Combined Influence of Substrate Elasticity and Ligand Density on the Viability and Biophysical Properties of Hematopoietic Stem and Progenitor Cells. Biomaterials 2012, 33, 4460-4468.

(41) Katz, B. Z.; Zamir, E.; Bershadsky, A.; Kam, Z.; Yamada, K. M.; Geiger, B. Physical State of the Extracellular Matrix Regulates the Structure and Molecular Composition of Cell-Matrix Adhesions. Mol. Biol. Cell 2000, 11, 1047-1060.

(42) Kishore, V.; Bullock, W.; Sun, X.; Van Dyke, W.; Akkus, O. Tenogenic Differentiation of Human MSCs Induced by the Topography of Electrochemically Aligned Collagen Threads. Biomaterials 2012, 33, 2137-2144.

(43) Tong, W.; Shen, W.; Yeung, C.; Zhao, Y.; Cheng, S.; Chu, P.; Chan, D.; Chan, G.; Cheung, K.; Yeung, K.; Lam, Y. Functional Replication of the Tendon Tissue Microenvironment by a Bioimprinted Substrate and the Support of Tenocytic Differentiation of Mesenchymal Stem Cells. Biomaterials 2012, 33, 7686-7698.

(44) Checa, A. G.; Esteban-Delgado, F. J.; Ramirez-Rico, J.; Rodriguez-Navarro, A. B. Crystallographic Reorganization of the Calcitic Prismatic Layer of Oysters. J. Struct. Biol. 2009, 167, 261-270.

(45) Currey, J. D. The Design of Mineralised Hard Tissues for their Mechanical Functions. J. Exp. Biol. 1999, 202, 3285-3294.

(46) Falini, G.; Albeck, S.; Weiner, S.; Addadi, L. Control of Aragonite or Calcite Polymorphism by Mollusk Shell Macromolecules. Science 1996, 271, 67-69.

(47) Kaplan, D. L. Mollusc Shell Structures: Novel Design Strategies for Synthetic Materials. Curr. Opin. Solid State Mater. Sci. 1998, 3, 232-236.

(48) Lin, A. Y.-M.; Chen, P.-Y.; Meyers, M. A. The Growth of Nacre in the Abalone Shell. Acta Biomater. 2008, 4, 131-138.

(49) Mann, S. Biomineralization and Biomimetic Materials Chemistry. J. Mater. Chem. 1995, 5, 935-946.

(50) Cusack, M.; Freer, A. Biomineralization: Elemental and Organic Influence in Carbonate Systems. Chem. Rev. 2008, 108, 4433-4454.

(51) Arrington, E. D.; Smith, W. J.; Chambers, H. G.; Bucknell, A. L.; Davino, N. A. Complications of Iliac Crest Bone Graft Harvesting. Clin. Orthop. Relat. Res. 1996, 329, 300-309. 
(52) McBeath, R.; Pirone, D. M.; Nelson, C. M.; Bhadriraju, K.; Chen, C. S. Cell Shape, Cytoskeletal Tension, and Rhoa Regulate Stem Cell Lineage Commitment. Dev. Cell 2004, 6, 483-495.

(53) Alakpa, E. V.; Jayawarna, V.; Lampel, A.; Burgess, K. V.; West, C. C.; Bakker, S. C. J.; Roy, S.; Javid, N.; Fleming, S.; Lamprou, D. A.; Yang, J.; Miller, A.; Urquhart, A. J.; Pim, W. J. M.; Hunt, N. T.; Péault, B.; Ulijn, R.; Dalby, M. J. Tuneable Supramolecular Hydrogels for Selection of Lineage Guiding Metabolites in Stem Cell Cultures. Chem. 2016, 1, 298-319.

(54) Leader, D. P.; Burgess, K.; Creek, D.; Barrett, M. P. Pathos: A Web Facility that Uses Metabolic Maps to Display Experimental Changes in Metabolites Identified by Mass Spectrometry. Rapid Commun. Mass Spectrom. 2011, 25, 3422-3426.

(55) Bublitz, C.; Grollman, A. P.; Lehninger, A. L. The Enzymic Conversion of D-Glucuronate to L-Ascorbate and L-Xylulose in Animal Tissues. Biochim. Biophys. Acta 1958, 27, 221-222.

(56) Eleftheriades, E. G.; Ferguson, A. G.; Spragia, M. L.; Samarel, A. M. Prolyl Hydroxylation Regulates Intracellular Procollagen Degradation in Cultured Rat Cardiac Fibroblasts. J. Mol. Cell. Cardiol. 1995, 27, 1459-1473.

(57) Rosenblat, G.; Willey, A.; Zhu, Y. N.; Jonas, A.; Diegelmann, R. F.; Neeman, I.; Graham, M. F. Palmitoyl Ascorbate: Selective Augmentation Of Procollagen Mrna Expression Compared with LAscorbate in Human Intestinal Smooth Muscle Cells. J. Cell. Biochem. 1999, 73, 312-320.

(58) Sullivan, T. A.; Uschmann, B.; Hough, R.; Leboy, P. S. Ascorbate Modulation of Chondrocyte Gene-Expression is Independent of its Role in Collagen Secretion. J. Biol. Chem. 1994, 269, 2250022506.

(59) Hur, S. J.; Park, Y. Effect of Conjugated Linoleic Acid on Bone Formation and Rheumatoid Arthritis. Eur. J. Pharmacol. 2007, 568, $16-24$.

(60) Merrill, A. H.; Schroeder, J. J. Lipid Modulation of CellFunction. Annu. Rev. Nutr. 1993, 13, 539-559.

(61) Rahman, M. M.; Bhattacharya, A.; Banu, J.; Fernandes, G. Conjugated Linoleic Acid Protects Against Age-Associated Bone Loss in C57BL/6 Female Mice. J. Nutr. Biochem. 2007, 18, 467-474.

(62) McManus, L. L.; Burke, G. A.; McCafferty, M. M.; O'Hare, P.; Modreanu, M.; Boyd, A. R.; Meenan, B. J. Raman Spectroscopic Monitoring of the Osteogenic Differentiation of Human Mesenchymal Stem Cells. Analyst 2011, 136, 2471-2481.

(63) Morris, M. D.; Mandair, G. S. Raman Assessment of Bone Quality. Clin. Orthop. Relat. Res. 2011, 469, 2160-2169.

(64) Awonusi, A.; Morris, M. D.; Tecklenburg, M. M. J. Carbonate Assignment and Calibration in the Raman Spectrum of Apatite. Calcif. Tissue Int. 2007, 81, 46-52.

(65) Dehring, K. A.; Crane, N. J.; Smukler, A. R.; McHugh, J. B.; Roessler, B. J.; Morris, M. D. Identifying Chemical Changes in Subchondral Bone Taken from Murine Knee Joints Using Raman Spectroscopy. Appl. Spectrosc. 2006, 60, 1134-1141.

(66) Kazanci, M.; Fratzl, P.; Klaushofer, K.; Paschalis, E. P. Complementary Information on in Vitro Conversion of Amorphous (Precursor) Calcium Phosphate to Hydroxyapatite from Raman Microspectroscopy and Wide-Angle X-Ray Scattering. Calcif. Tissue Int. 2006, 79, 354-359.

(67) Mandair, G. S.; Morris, M. D. Contributions of Raman Spectroscopy to the Understanding of Bone Strength. BoneKEy Rep. 2015, 4, 620-620.

(68) Movasaghi, Z.; Rehman, S.; Rehman, I. U. Raman Spectroscopy of Biological Tissues. Appl. Spectrosc. Rev. 2007, 42, 493-541.

(69) Penel, G.; Delfosse, C.; Descamps, M.; Leroy, G. Composition of Bone and Apatitic Biomaterials as Revealed by Intravital Raman Microspectroscopy. Bone 2005, 36, 893-901.

(70) Downes, A.; Elfick, A. Raman Spectroscopy and Related Techniques in Biomedicine. Sensors 2010, 10, 1871-1889.

(71) McManus, L. L.; Bonnier, F.; Burke, G. A.; Meenan, B. J.; Boyd, A. R.; Byrne, H. J. Assessment of an Osteoblast-Like Cell Line as a Model for Human Primary Osteoblasts Using Raman Spectroscopy. Analyst 2012, 137, 1559-1569.
(72) Lakshmi, R. J.; Alexander, M.; Kurien, J.; Mahato, K. K.; Kartha, V. B. Osteoradionecrosis (ORN) of the Mandible: a Laser Raman Spectroscopic Study. Appl. Spectrosc. 2003, 57, 1100-1116.

(73) Buchwald, T.; Kozielski, M.; Szybowicz, M. Determination of Collagen Fibers Arrangement in Bone Tissue by Using Transformations of Raman Spectra Maps. Spectroscopy 2012, 27, 107-117.

(74) Wopenka, B.; Pasteris, J. D. A Mineralogical Perspective on the Apatite in Bone. Mater. Sci. Eng., C 2005, 25, 131-143.

(75) Crane, N. J.; Popescu, V.; Morris, M. D.; Steenhuis, P.; Ignelzi, M. A., Jr. Raman Spectroscopic Evidence for Octacalcium Phosphate and Other Transient Mineral Species Deposited During Intramembranous Mineralization. Bone 2006, 39, 434-442.

(76) Stewart, S.; Shea, D. A.; Tarnowski, C. P.; Morris, M. D.; Wang, D.; Franceschi, R.; Lin, D. L.; Keller, E. Trends in Early Mineralization of Murine Calvarial Osteoblastic Cultures: a Raman Microscopic Study. J. Raman Spectrosc. 2002, 33, 536-543.

(77) Gentleman, E.; Swain, R. J.; Evans, N. D.; Boonrungsiman, S.; Jell, G.; Ball, M. D.; Shean, T. A. V.; Oyen, M. L.; Porter, A.; Stevens, M. M. Comparative Materials Differences Revealed in Engineered Bone as a Function of Cell-Specific Differentiation. Nat. Mater. 2009, $8,763-770$

(78) Kunstar, A.; Leferink, A. M.; Okagbare, P. I.; Morris, M. D.; Roessler, B. J.; Otto, C.; Karperien, M.; Van Blitterswijk, C. A.; Moroni, L.; van Apeldoorn, A. A. Label-Free Raman Monitoring of Extracellular Matrix Formation in Three-Dimensional Polymeric Scaffolds. J. R. Soc., Interface 2013, 10, 20130464.

(79) McCreadie, B. R.; Morris, M. D.; Chen, T.-c.; Rao, D. S.; Finney, W. F.; Widjaja, E.; Goldstein, S. A. Bone Tissue Compositional Differences in Women With and Without Osteoporotic Fracture. Bone 2006, 39, 1190-1195.

(80) Yerramshetty, J. S.; Akkus, O. The Associations Between Mineral Crystallinity and the Mechanical Properties of Human Cortical Bone. Bone 2008, 42, 476-482.

(81) Reilly, D. T.; Burstein, A. H. Review Article - Mechanical Properties of Cortical Bone. J. Bone Jt. Surg., Am. 1974, 56, 10011022.

(82) Bala, Y.; Farlay, D.; Boivin, G. Bone Mineralization: from Tissue to Crystal in Normal and Pathological Contexts. Osteoporosis Int. 2013, 24, 2153-2166.

(83) Bi, X.; Patil, C. A.; Lynch, C. C.; Pharr, G. M.; MahadevanJansen, A.; Nyman, J. S. Raman and Mechanical Properties Correlate at Whole Bone- and Tissue-Levels in a Genetic Mouse Model. J. Biomech. 2011, 44, 297-303.

(84) Schefe, J. H.; Lehmann, K. E.; Buschmann, I. R.; Unger, T.; Funke-Kaiser, H. Quantitative Real-Time RT-PCR Data Analysis: Current Concepts and the Novel "Gene Expression's C-T Difference" Formula. J. Mol. Med. 2006, 84, 901-910.

(85) Creek, D. J.; Jankevics, A.; Burgess, K. E.; Breitling, R.; Barrett, M. P. IDEOM: an Excel Interface for Analysis of LC-MS-based Metabolomics Data. Bioinformatics 2012, 28, 1048-1049.

(86) Scheltema, R. A.; Jankevics, A.; Jansen, R. C.; Swertz, M. A.; Breitling, R. PeakML/mzMatch: a File Format, Java library, R Library, and Tool-Chain for Mass Spectrometry Data Analysis. Anal. Chem. 2011, 83, 2786-93.

(87) Compton, S. J.; Jones, C. G. Mechanism of Dye Response and Interference in the Bradford Protein Assay. Anal. Biochem. 1985, 151, 369-374.

(88) Creek, D. J.; Jankevics, A.; Breitling, R.; Watson, D. G.; Barrett, M. P.; Burgess, K. E. Toward Global Metabolomics Analysis with Hydrophilic Interaction Liquid Chromatography-Mass Spectrometry: Improved Metabolite Identification by Retention Time Prediction. Anal. Chem. 2011, 83, 8703-8710.

(89) Xia, J.; Sinelnikov; Igor, V.; Han, B.; Wishart, D. MetaboAnalyst 3.0-Making Metabolomics More Meaningful. Nucleic Acids Res. 2015, 43, W251-W257. 